\title{
Convulsant Actions of 4-Aminopyridine on the Guinea-Pig Olfactory Cortex Slice
}

\author{
MARTIN GALVAN, PETER GRAFE and GERRIT TEN BRUGGENCATE \\ Department of Physiology, University of Munich, Pettenkoferstrasse 12, 8000 Munich 2 (F.R.G.)
}

(Accepted October 29th, 1981)

Key words: 4-aminopyridine - convulsant - olfactory cortex — diphenylhydantoin — inhibitory postsynaptic potential

\begin{abstract}
The effects of bath-applied 4-aminopyridine on neurones and extracellular potassium and calcium concentrations were recorded in slices of guinea-pig olfactory cortex. Neurones were orthodromically activated by stimulating the lateral olfactory tract. 4Aminopyridine (3-10 $\mu \mathrm{M}$ ) had the following effects: (1) an increase in the frequency and amplitude of spontaneous postsynaptic potentials; (2) a prolongation and oscillatory behaviour of orthodromically evoked postsynaptic potentials; (3) induction of spontaneous or stimulus-evoked seizure-type discharges which were accompanied by large rises in extracellular potassium and falls in calcium concentration; (4) a prolongation of the lateral olfactory tract population fibre spike. Prior to paroxysmal depolarization, membrane potential, input resistance and soma spike duration were unaffected. In the seconds before seizure discharges, a late hyperpolarizing potential (evoked by orthodromic stimulation) was reduced in amplitude or abolished. Diphenylhydantoin (50 $\mu \mathrm{M})$ or magnesium ions $(5 \mathrm{mM})$ prevented paroxysmal activity. Our results show that 4-aminopyridine can produce seizure-type discharges in a brain slice preparation. The role of increased spontaneous potentials and possible loss of synaptic inhibition as causal factors for such discharges is discussed.
\end{abstract}

\section{INTRODUCTION}

The actions of 4-aminopyridine (4-AP) on invertebrate and vertebrate excitable tissue has attracted a great deal of interest. This compound, whose best characterized action seems to be a blockade of axonal potassium channels ${ }^{23,31,32,41,43,45}$, has powerful facilitatory actions on synaptic transmitter release in the peripheral and central nervous systems $5,11,18,19,21,41,44$. These effects have been extensively studied at neuromuscular junctions, where 4AP causes an increase in quantal content, whilst having little effect on the probability of transmitter release or on the postsynaptic membrane (see ref. 41 for refs.). Detailed experiments on the central nervous system are so far limited to the cat spinal cord, where a facilitation of mono- and polysynaptic reflexes has been observed ${ }^{18,21}$.

Before the cellular actions of 4-AP were investigated, it was known to be a lethal convulsant in frogs and mice ${ }^{9,15}$. Recent experiments have shown that the related compound 3-aminopyridine causes convulsant discharges in cortical neurones of anaesthetized cats ${ }^{1,40}$; tonic-clonic seizures in humans result from 4-AP poisoning ${ }^{39}$. The exact mechanism underlying this action is unknown, although it is possible that the block of axonal potassium channels is involved. Despite this toxicity, and the lack of knowledge regarding its actions on supraspinal systems, 4-AP has been clinically tested on a number of diseases of neuromuscular transmission. These include botulism, myasthenia gravis and the EatonLambert myasthenic syndrome ${ }^{41}$. There is also hope that increased transmitter release at central synapses and/or a prolongation of action potentials might lead to an improvement in some CNS diseases ${ }^{37}$.

In order to investigate the action of this compound on cortical neurones and also to gain some insight into convulsive phenomena in a mammalian brain slice preparation, we have made a study of the actions of 4-AP on neurones in the olfactory cortex slice of guinea-pigs.

A preliminary account of some of these results has already been published ${ }^{12}$. 


\section{METHODS}

Male or female guinea-pigs $(\approx 350 \mathrm{~g}$ ) were decapitated and the brain was rapidly removed onto wet filter paper. Using a plastic guide and a bowcutter, a surface slice (approximately $500 \mu \mathrm{m}$ thick) of olfactory cortex was cut and placed in oxygenated Krebs' solution at $30^{\circ} \mathrm{C}$. The time between decapitation and placement of the slice in Krebs solution was $85 \pm 11 \mathrm{~s}$ (mean \pm S.D.; $\mathrm{n}=15$ ). After a few hours preincubation, slices were transferred to a small temperature controlled Perspex bath, sandwiched between two nylon meshes and completely submerged. Oxygenated Krebs' solution at $30{ }^{\circ} \mathrm{C}$ was pumped through the bath at $8-10 \mathrm{ml} / \mathrm{min}$; bath exchange time was about $30 \mathrm{~s}$.

Stimulation of the lateral olfactory tract (LOT) and intracellular recording were performed using conventional methods previously described ${ }^{7,10}$. Cells were impaled with $4 \mathrm{M}$ potassium acetate filled microelectrodes in the prepiriform or periamygdaloid regions at depths (from the pial surface) between 180 and $494 \mu \mathrm{m}(377 \pm 99 ;$ mean \pm S.D., $\mathrm{n}=$ 20). Extracellular field potentials were routinely monitered using a $3 \mathrm{M} \mathrm{NaCl}$ filled glass microelectrode (about 1-3 M $\Omega$ ) placed on the pial surface of the prepiriform area. Ion sensitive microelectrodes were constructed ${ }^{17,29}$ using $1.5 \mathrm{~mm}$ theta style glass, pulled to give tips of about $1.5 \mu \mathrm{m}$. One barrel was silanised by backfilling with a small amount of trichlormethylsilane, which was evaporated in a hot wire spiral. Ion exchanger was then injected into the sensitive side and after the tip had filled, the barrel was backfilled with appropriate electrolyte $(150 \mathrm{mM} \mathrm{KCl}$ or $150 \mathrm{mM} \mathrm{CaCl})$. The reference barrels were filled with $150 \mathrm{mM} \mathrm{NaCl}$. Electrodes were inserted into the prepiriform or periamygdaloid regions at a depth of about $300 \mu \mathrm{m}$; this point was estimated from the turnover of LOTevoked ' $\mathrm{N}$-wave'13,16 and approximately corresponds to the soma layer in this preparation.

Intracellularly recorded potentials were amplified using a conventional bridge-balance amplifier; ion signals were passed through high impedence FETs and then amplified. Subtraction of electrical signals common to both barrels of the ion sensitive electrodes was checked by injecting $20 \mathrm{mV}, 20 \mathrm{~ms}$ pulses through the recording bath; electrical subtraction was complete within a few milliseconds. All electrical signals were simultaneously displayed on a chart recorder and monitored on an oscilloscope. Data was stored on magnetic tape (Hewlett Packard; bandwidth DC $2.5 \mathrm{kHz}$ ) for later analysis. Some data was digitalized using a Nicolet Med 80 computer.

In a few experiments, the LOT was dissected free of the surrounding cortex. The central end was drawn into a suction electrode, which was connected through an appropriate amplifier to an oscilloscope and a digital averager. Stimulation of the peripheral end was effected via a pair of Pt electrodes. This method allows a recording of the LOT fibre tract potential, relatively uncontaminated by postsynaptic field potentials. In all experiments, the composition of the Krebs solution was as follows ( $\mathrm{mmol} / \mathrm{l})$ : $\mathrm{NaCl}, 118 ; \mathrm{KCl}, 3.0 ; \mathrm{NaHCO}_{3}, 25 ; \mathrm{NaH}_{2} \mathrm{PO}_{4}$. $\mathrm{H}_{2} \mathrm{O} 1.2 ; \mathrm{MgCl}_{2} \cdot 6 \mathrm{H}_{2} \mathrm{O}, 1.0 ; \mathrm{CaCl}_{2} \cdot 2 \mathrm{H}_{2} \mathrm{O}, 1.5$; Dglucose, 11; this solution was continuously gassed with $95 \% \mathrm{O}_{2} / 5 \% \mathrm{CO}_{2} ; \mathrm{pH}=7.4$.

Drug sources were as follows: 4-aminopyridine (EGA-Chemie, Steinheim); diphenylhydantoin sodium (Parke-Davis); $\mathrm{K}^{+}$-exchanger (Corning 477317); $\mathrm{Ca}^{2+}$-exchanger (gift from Prof. Simon, ETA Zurich).

\section{RESULTS}

\section{Events preceding convulsant discharges}

Successful intracellular recordings were made from 26 neurones, which had the following passive membrane properties: membrane potential, -75 $\mathrm{mV} \pm 8.8(\mathrm{n}=25)$; input resistance, $45 \mathrm{M} \Omega \pm 25$ $(\mathrm{n}=19)$; action potential amplitude, $99 \mathrm{mV} \pm 15$

\section{TABLE I}

Effects of 4-aminopyridine on membrane potential and input resistance of olfactory cortex neurones

$E_{m}$, membrane potential; $R_{m}$ input resistance; $n=$ number of cells.

\begin{tabular}{|c|c|c|c|c|}
\hline \multirow{2}{*}{$\begin{array}{l}\text { Solution } \\
\text { (time of application) }\end{array}$} & $E_{m}$ & \multirow[t]{2}{*}{$n$} & $R_{m}$ & \multirow[t]{2}{*}{$n$} \\
\hline & $\begin{array}{l}(m V \\
\pm S . E . M .)\end{array}$ & & $\begin{array}{l}(M \Omega \\
\pm S . E . M .\end{array}$ & \\
\hline Control & $-76 \pm 2$ & (6) & $52 \pm 11$ & $(8)$ \\
\hline $4-\mathrm{AP} 3 \mu \mathrm{mol} / 1+10 \mathrm{~min}$ & $-73 \pm 4$ & (6) & $56 \pm 13$ & (8) \\
\hline Control & $-79 \pm 1$ & (12) & $45 \pm 9$ & (7) \\
\hline $4-\mathrm{AP} 10 \mu \mathrm{mol} / 1+5 \mathrm{~min}$ & $-74 \pm 2$ & (12) & $46 \pm 8$ & (7) \\
\hline
\end{tabular}




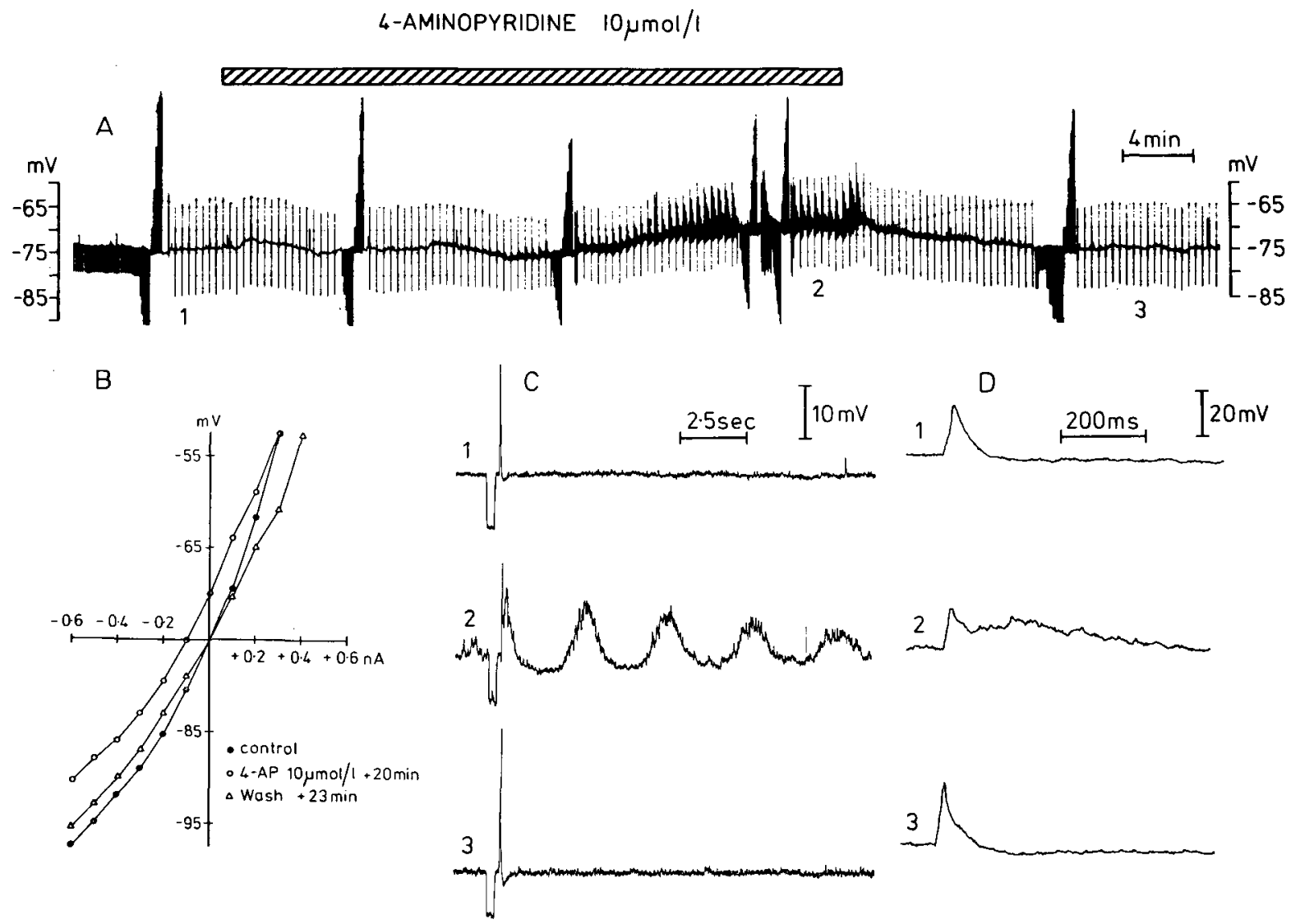

Fig. 1. Actions of $10 \mu \mathrm{M}$ 4-aminopyridine on passive membrane properties and orthodromically-evoked postsynaptic potentials. A: a DC recording of membrane potential and the hatched bar indicates the time of 4-AP application. The fast downward deflections are responses to injected current and the upward deflections result from LOT stimulation. The large black deflections were produced by injecting a series of current pulses in order to assess the cell's current voltage relationship. B: shows the current-voltage curves constructed from such current injections at the times indicated in the lower right quadrant. It is noticeable that after 20 min superfusion with 4-AP (o), there was a slight depolarization but no major change in slope resistance. C: the membrane response to single supramaximal stimuli of the lateral olfactory tract, recorded at the times indicated by the numbers in A. These recordings were made on a very slow time base and show initially a hyperpolarizing electrotonic potential followed by the orthodromic stimulation. On this time scale the initial EPSP is compressed. This is illustrated on an expanded time scale in D. It can be seen that during 4-AP, the EPSP was reduced in amplitude but prolonged in duration and followed by several after oscillations of membrane potential. These effects were reversible by washing in normal Krebs' solution.

$(\mathrm{n}=19)$; recording duration, $153 \mathrm{~min} \pm 132(\mathrm{n}=$ 26 ); all values mean $\pm S . D$.

4-AP was applied via the bathing solution at a concentration of either 3 or $10 \mu \mathrm{mol} / \mathrm{l}$. In the first 5-10 min of superfusion we could measure no significant change in membrane potential or input resistance (Table I; Fig. 1). However, after a few minutes we observed an increase in the amplitude and frequency of spontaneous postsynaptic potentials (Fig. 2). These potentials, which were usually depolarizing, sometimes exceeded spike threshold. Injection of depolarizing current during this phase sometimes led to repetitive cell discharges. Fig. 2 illustrates that the increase in spontaneous potentials was slightly delayed, and reached a maximum value after about $10 \mathrm{~min}$ of superfusion. Sometimes, the frequency of such spontaneous potentials was sufficient to slightly depolarize the recorded neurone although a change in input resistance was rarely noted (Fig. 1A, B). It was normally the case that after 5-10 min of superfusion with $10 \mu \mathrm{mol} / \mathrm{l} 4-\mathrm{AP}$, the LOT-evoked postsynaptic potentials were altered. Thus, a single LOT stimulus, which under control conditions only evokes a single EPSP, spike, IPSP complex ${ }^{33}$, elicited a series of membrane potential oscillations which slowly (over seconds) de- 

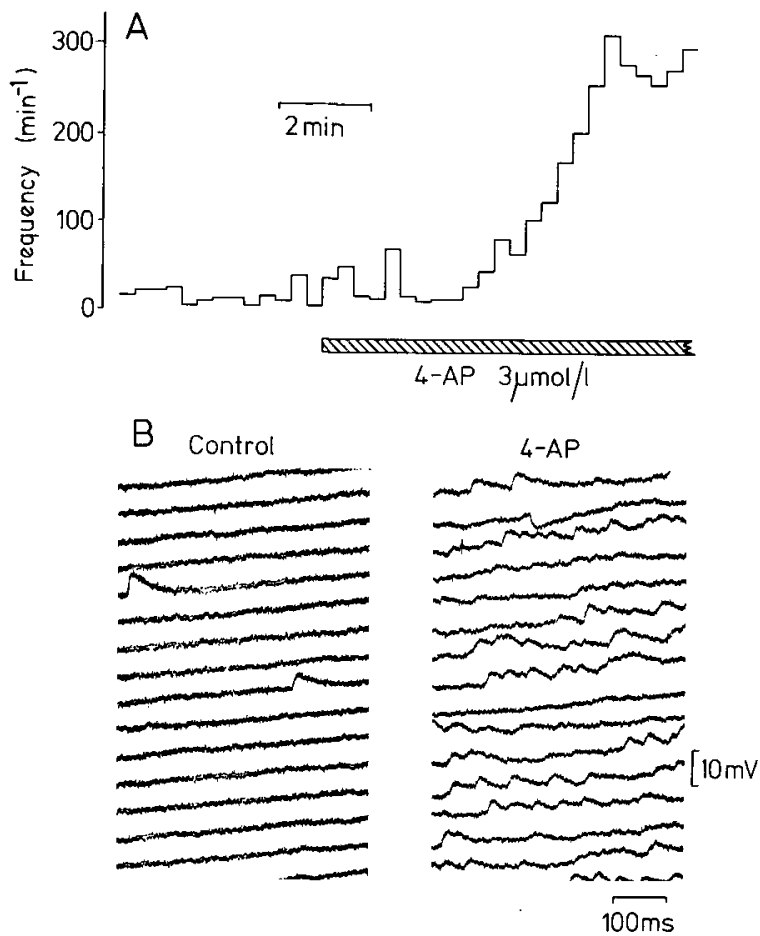

Fig. 2. Effect of $3 \mu \mathrm{M} 4$-aminopyridine on spontaneous postsynaptic potentials. A: a computer plot of the frequency of spontaneous potentials. Ordinates, number of potentials per minute; the hatched bar indicates the duration of the drug application. B: high amplification oscilloscope records of the membrane potential before and during 4-AP.

cayed (Fig. 1C). This effect was easily reversible by washing. Additionally we also observed that the initial EPSP was often reduced in amplitude (Fig. 1D).

Measurements of extracellular potassium and calcium concentrations showed that the initial phase of enhanced spontaneous transmitter release was accompanied by a small increase in $\mathrm{K}^{+}$and decrease in $\mathrm{Ca}^{2+}$ concentrations (Figs. 5 and $9 \mathrm{~A}$ ).

\section{Convulsant actions of 4-aminopyridine}

In all 24 slices which we studied, prolonged applications of $10 \mu \mathrm{mol} / 14$-AP led to repetitive convulsant discharges. These were characterized, at the single cell level, by cell depolarization $(20-40 \mathrm{mV})$, prolonged bursts of spikes followed by a period of depression during which the cell repolarized and spontaneous potentials disappeared (Figs. 3C, D, 7A and $9 \mathrm{~B}, \mathrm{C})$. It was usually the case that just before the onset of such discharges the membrane potential exhibited spontaneous membrane potential oscillations (sometimes up to $10 \mathrm{mV}$ in amplitude). Spectral analysis performed using a $16 \mathrm{~Hz}$ low pass filter indicated that the main power of these oscillations was at $0.29 \pm 0.04 \mathrm{~Hz}$ (mean \pm S.D.; $\mathrm{n}=13$ ).

Analysis of passive membrane properties revealed that just prior to seizure discharges, the membrane potential was virtually unaltered and the current voltage relationship (assessed by injecting hyperpolarizing current pulses of increasing amplitude) was unchanged (Fig. 4A). Cell excitability, as judged from the number of spikes elicited by a depolarizing current pulse, was either increased, decreased or unchanged (see, for example, Fig. 4C). During the paroxysmal depolarization, the cell input resistance was reduced (Fig. 4A, C), and this probably accounts for the disappearance of spontaneous potentials. In several experiments repetitive seizure discharges continued for periods of up to $30 \mathrm{~min}$ (the complete duration of 4-AP application).

\section{Ionic changes during convulsant activity}

The seizure discharges recorded from single neurones in the olfactory cortex slice were always accompanied by large increases in extracellular potassium and decreases in extracellular calcium (Figs. 3,5 and 9). Baseline concentrations in our preparation were 3.0 and $1.5 \mathrm{mmol} / 1$ respectively. Potassium rose to a value of $9.9 \pm 2.9$ (mean \pm S.D.; 43 trials in 9 slices) and calcium fell to about $1.2 \mathrm{mmol} / 1$ ( 7 trials in 2 slices). It was frequently noticed that simultaneous with the above mentioned membrane potential oscillations, ion concentrations exhibited rhythmic changes (see, for example, Fig. 5). In some experiments we measured potassium in two distinct regions of the slice (separated by several millimeters) and these experiments indicated that the seizure discharges occurred simultaneously in all regions. No evidence for a 'spreading depression' type phenomenon was obtained.

\section{Changes in lateral olfactory tract evoked potentials}

The usual change observed was a reduction in the amplitude of the LOT-evoked EPSP, accompanied by a marked prolongation of the postsynaptic response (Fig. 1C, D). We analyzed in detail changes occurring in a further LOT-evoked postsynaptic potential (known as the LHP). This late hyperpolarizing potential, briefly described by Constanti et 
al. ${ }^{7}$ appears to be an IPSP additional to the $\mathrm{Cl}^{-}$ mediated IPSP described by Scholfield (ref. 33, see also ref. 27). Our experiments showed that this potential is accompanied by an approximately $50 \%$ decrease in input resistance, is very sensitive to repetitive orthodromic stimulation, and is reduced in amplitude when the bath potassium was raised to 8 or $10 \mathrm{mmol} / \mathrm{l}$ (Fig. 6). Since the LHP reversed $10-15 \mathrm{mV}$ negative to resting potential ${ }^{7}$, it may result from a synaptically induced increase in potassium conductance (cf. ref. 30). In 4 cells where this potential was recorded, we observed that 4-AP reduced its amplitude. Fig. 7 illustrates an example of this and shows the following. In the seconds preceding seizure discharge, this potential was reduced and subsequently abolished. In the period between two seizure discharges, it reappeared only to disappear again about $20 \mathrm{~s}$ before the second discharge. It is therefore possible that this represents a rhythmic loss of inhibition, synchronous in time with the onset of cell seizure discharge.

\section{Action of 4-aminopyridine on the axons of the lateral olfactory tract}

In 4 experiments we measured the population spike from isolated lateral olfactory tracts (free of surrounding cortex). The results (illustrated in Fig. 8) revealed that in micromolar concentrations, 4-AP significantly prolonged the population spike by up to $300 \%$. This was accompanied by some reduction in amplitude.

\section{Action of some antagonists of seizure discharges}

In order to further characterize the nature of the abnormal discharges we examined their sensitivity to known blockers of synaptic transmission and also
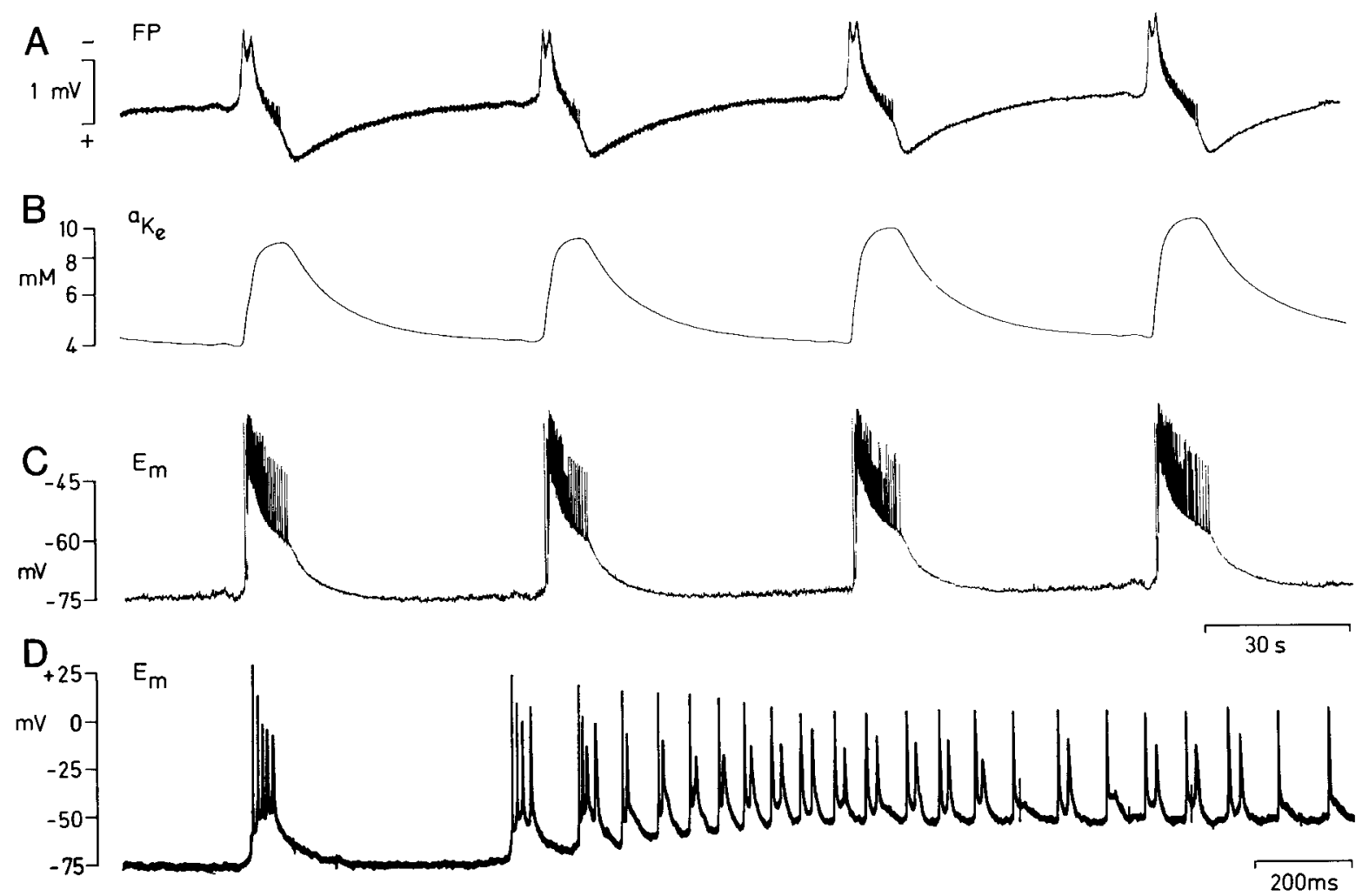

Fig. 3. Rhythmic seizures in a slice of olfactory cortex during superfusion with $10 \mu \mathrm{M}$ 4-aminopyridine. A, B and C: simultaneous recordings of (from the top downwards) extracellular field potential, extracellular potassium concentration and intracellularly recorded membrane potential. The double-barrelled potassium electrode was located in the middle of the slice. It can be seen that about every $30 \mathrm{~s}$, the cell showed a depolarization on which bursts of spikes were superimposed. In $\mathrm{C}$ these spikes are attenuated in amplitude due to the recorder response time. Line D shows a fast and accurate recording of the initial phase of the first paroxysmal depolarization. Synchronous with the cell discharge was a large rise in potassium and a corresponding change in field potential; this indicates that more than the recorded cell underwent such a paroxysmal depolarization. 

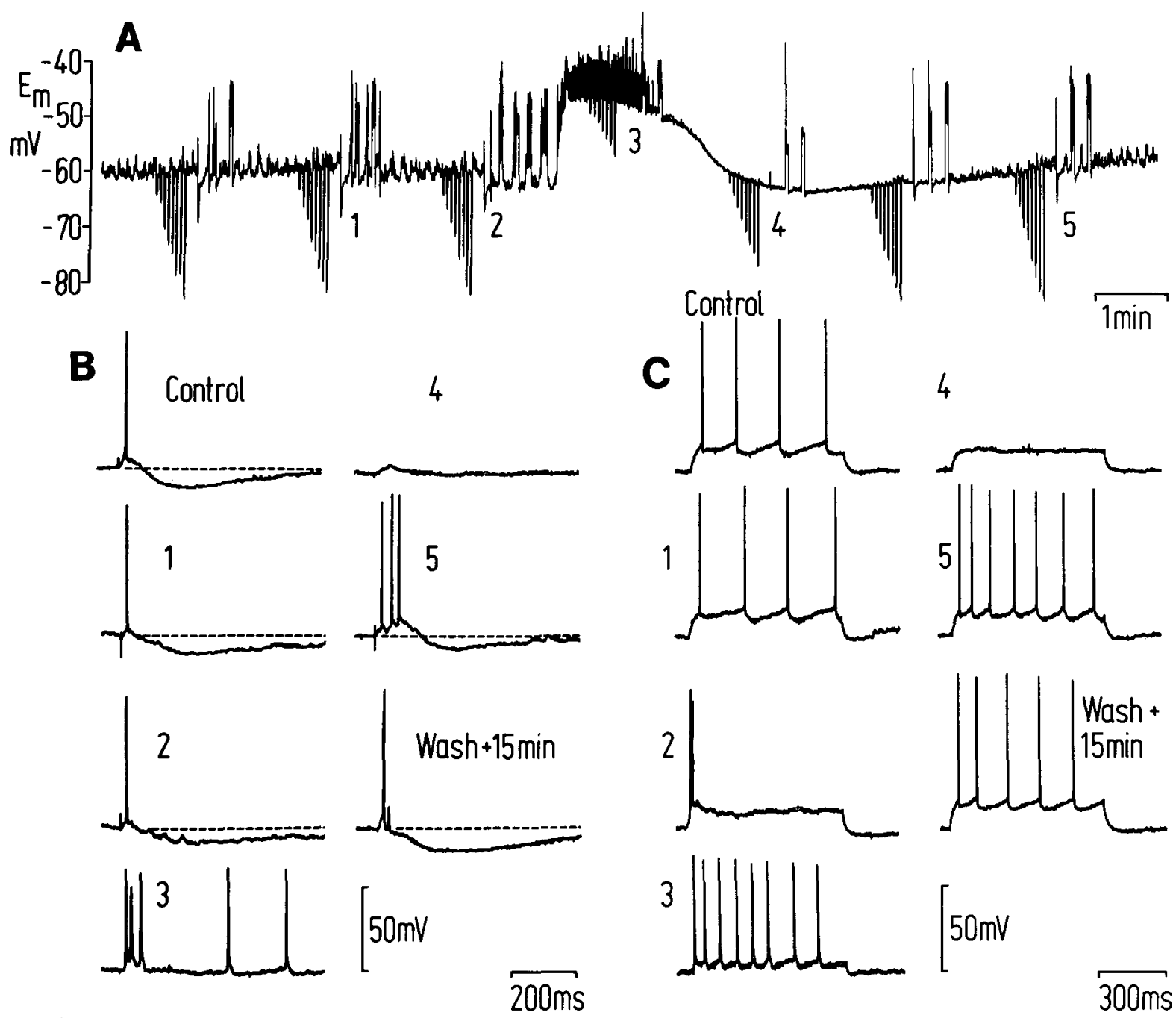

Fig. 4. Changes in membrane potential, cell excitability and orthodromic response in the minutes before, during and after a paroxysmal depolarization induced by application of $5 \mu \mathrm{M}$ 4-aminopyridine. The illustrated section begins $9 \mathrm{~min}$ after 4-AP application. A complex sequence of pulses was applied to the cell as follows: a ser ies of hyperpolarizing current pulses (the first was $0.075 \mathrm{nA}$ and each subsequent pulse increments by this amount); a single LOT stimulus ( $50 \mathrm{~V} ; 0.1 \mathrm{~ms})$; a depolarizing current pulse $(0.3 \mathrm{nA})$. This sequence repeated every $20 \mathrm{~s}$. At the times indicated by the numbers in A, fast oscilloscope sweeps were digitalized and plotted on an X-Y plotter. B: the responses to LOT stimulation. C: the membrane response to the injection of a depolarizing current pulse. The controls were recorded before application of 4-AP. Spikes are attenuated in amplitude in A due to recorder response time. Note how during the seizure the membrane resistance falls, although the cell fires repetitively in response to depolarizing current (C3) or orthodromic stimulation (B3). It can also be seen that the late hyperpolarizing potential is reduced in amplitude shortly before seizure onset (B2), and that the spontaneous potentials are absent for several minutes after paroxysmal depolarization.

the anticonvulsant diphenylhydantoin. Fig. 9 illustrates the results of two such experiments. Part A shows a simultaneous recording of membrane potential and extracellular potassium. Application of $10 \mu \mathrm{mol} / 14-\mathrm{AP}$ (without LOT stimulation) led to an increase in spontaneous potentials followed by rhythmic seizure discharges. These were quickly and reversibly abolished by adding $5 \mathrm{mmol} / 1 \mathrm{MgCl}_{2}$ to the bathing solution. Part B illustrates that $50 \mu \mathrm{mol} / 1$ diphenylhydantoin could also block seizure discharges. This finding was confirmed in 8 further experiments. It should be noted that in both cases the increased spontaneous activity was not fully suppressed by these antagonists. We have consis- 
tently found that prior application of these substances can completely prevent the increase in spontaneous potentials induced by 4-AP. The reason for this will be investigated in future experiments.

\section{DISCUSSION}

4-Aminopyridine is a potent blocker of delayed rectifier channels in a variety of invertebrate $23,31,32$, ${ }^{45}$ and also vertebrate ${ }^{43}$ axons. It is also a relatively selective blocker of transient outward current in molluscan neurones (A-current ${ }^{38,42}$ ) and sheep Purkinje fibres $\left(\mathrm{I}_{t 0}{ }^{8}\right)$. Other basic membrane ac- tions have been suggested: (a) a modification of sodium channel permeability ${ }^{32}$; (b) a facilitation of calcium currents ${ }^{24}$. It is most probable that a complete understanding of the actions of 4-AP on such a complicated system as a brain slice requires far more knowledge about cell membrane behaviour than is, at present, available. However, some of the phenomena that we observed can be explained on the basis of today's knowledge. Our recordings in the olfactory cortex indicate that 4-AP induces an increase in spontaneous transmitter release at central synapses. This is similar to our findings with guanidine (another K-channel blocker ${ }^{10}$ ). Since there is
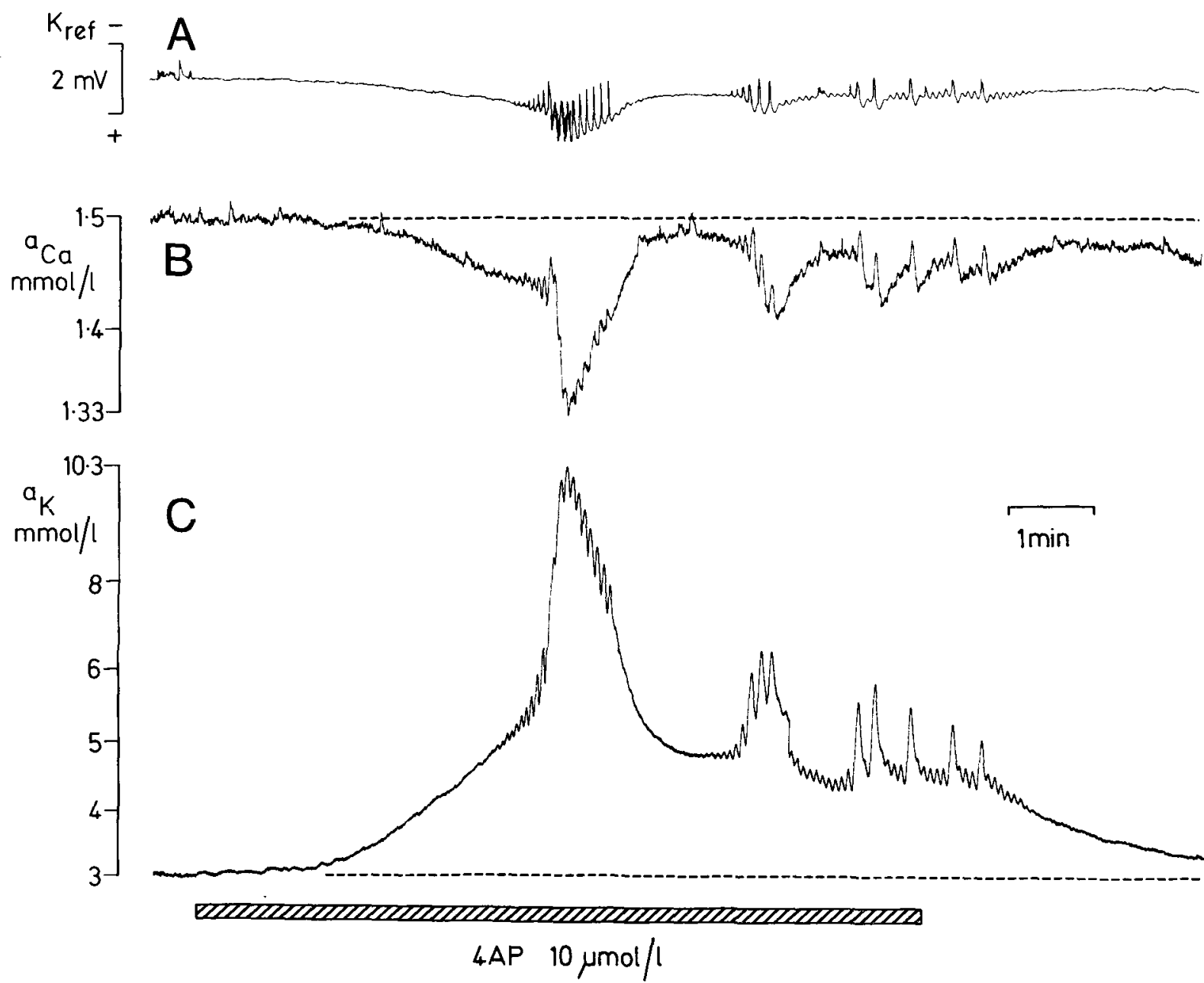

Fig. 5. Recordings of extracellular potassium (C) and calcium (B) made with two separate ion selective microelectrodes placed in the centre of an olfactory cortex slice. The DC recording from the potassium reference barrel is displayed in A (that from the calcium reference was essentially identical). Note how a few minutes after adding $10 \mu \mathrm{M} 4$-aminopyridine (hatched bar) the potassium rose and the calcium fell. Shortly before seizure onset there were marked oscillations of ion concentrations which to some extent continued after the large rises seen during the seizure. Following washout of 4-AP, ion levels quickly returned towards control levels and seizure activity terminated. Dashed lines indicate control ionic levels. 

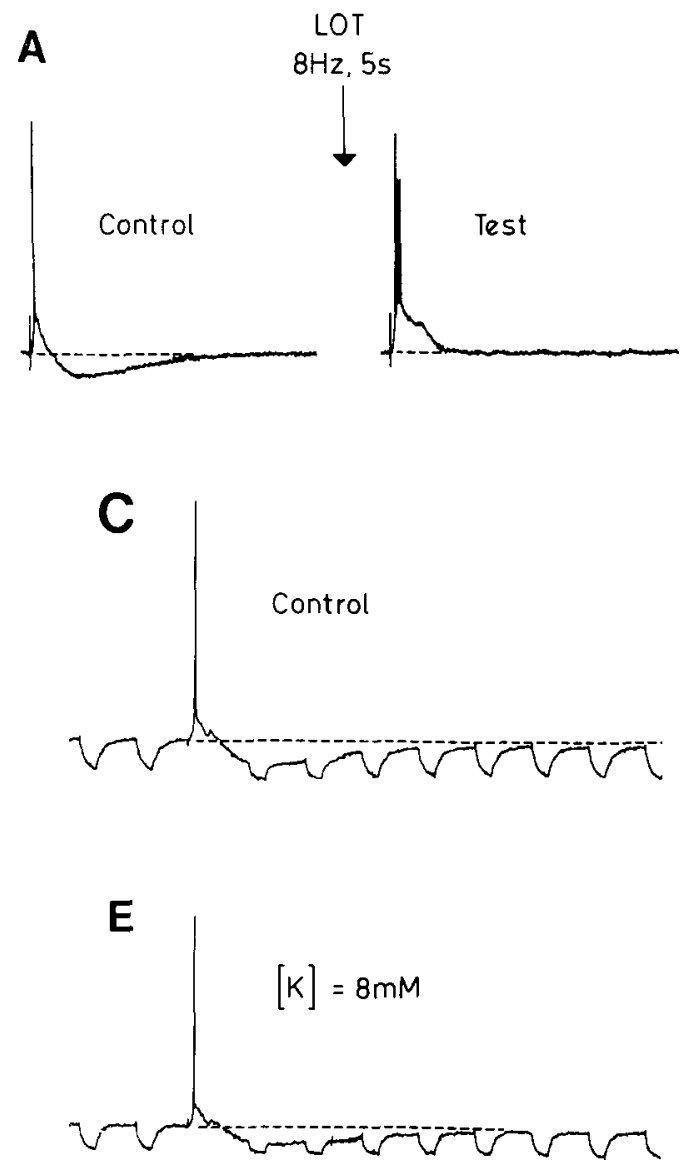

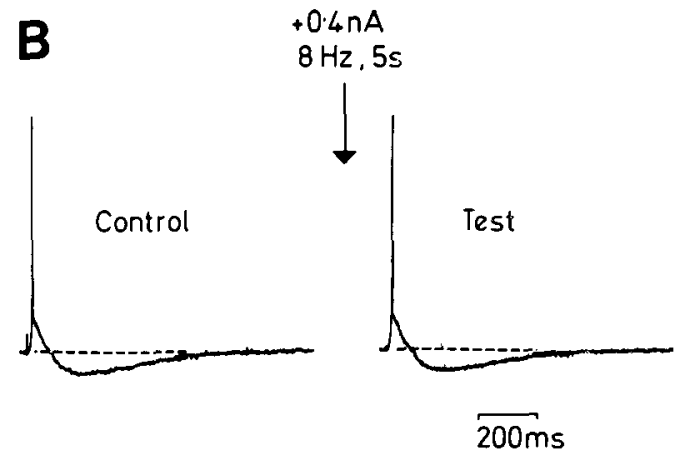

D
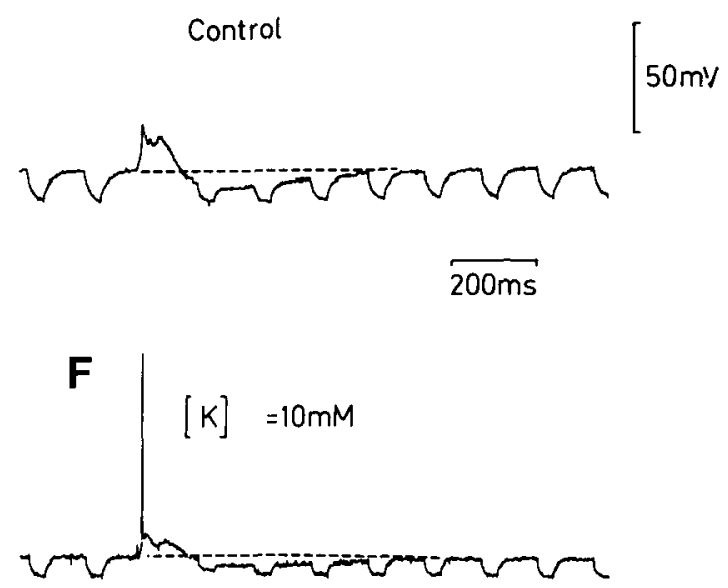

Fig. 6. Some properties of the 'late hyperpolarizing potential' (LHP) recorded from a neurone in the olfactory cortex slice. In A, the LOT was stimulated ( $50 \mathrm{~V} ; 0.1 \mathrm{~ms}$ ) every $15 \mathrm{~s}$ and between the control and test, a short tetanus $(8 \mathrm{~Hz}, 5 \mathrm{~s})$ was applied. This caused the LHP to be abolished for about $30 \mathrm{~s}$. B: a type of control experiment; between the control and test, only the recorded cell was tetanized. This was achieved by passing $0.4 \mathrm{nA}$ brief current pulses across the membrane at $8 \mathrm{~Hz}$. The duration of the pulse was such that one pulse elicited only one action potential. Under these conditions, the LHP elicited by a following LOT stimulus was unaffected. C: illustrates that the LHP is accompanied by a fall in membrane resistance. The downward deflections were produced by $40 \mathrm{~ms}, 0.3 \mathrm{nA}$ current pulses; the LOT stimulus is obvious from the spike. D: in the same cell the LHP could be observed even when the LOT stimulus was insufficient to elicit a soma spike. Note that the LHP was still accompanied by a reduction in membrane resistance. $\mathrm{E}$ and F: the LHP was reduced in amplitude when the bath potassium was raised to $8 \mathrm{mM}$ and $10 \mathrm{mM}$, respectively. Resting potential of this cell was $-90 \mathrm{mV} .8 \mathrm{mM}$ potassium depolarized the cell by $7 \mathrm{mV}$ and $10 \mathrm{mM}$ potassium by a further $8 \mathrm{mV}$.

now considerable evidence that such an enhancement of transmitter release occurs at a number of peripheral and central synapses, we feel that a common mechanism is involved. The most likely explanation is that 4-AP, through a block of some type of $\mathrm{K}^{+}$-channel, destabilizes presynaptic structures such that spontaneous spikes/depolarizations occur $^{38}$. The fact that such spontaneous release is tetrodotoxin (TTX) sensitive suggests that a facilitation of calcium currents (whether resting or voltage sensitive) is unlikely to be the primary mechanism of action. One consequence of an enhanced presynap- tic excitability might be repetitive firing of axons/ nerve terminals following a single nerve stimulus, as observed in lamprey giant Müller axons during application of guanidine ${ }^{25}$. It is possible that the postsynaptic membrane potential oscillations and their accompanying ion fluctuations result from such a presynaptic rhythmicity. Thus, when the axon membrane potential oscillates, this leads to periodic release of neurotransmitter, which depolarizes the recorded neurone. We often observed that bursts of spontaneous potentials were superimposed on the peaks of postsynaptically recorded mem- 

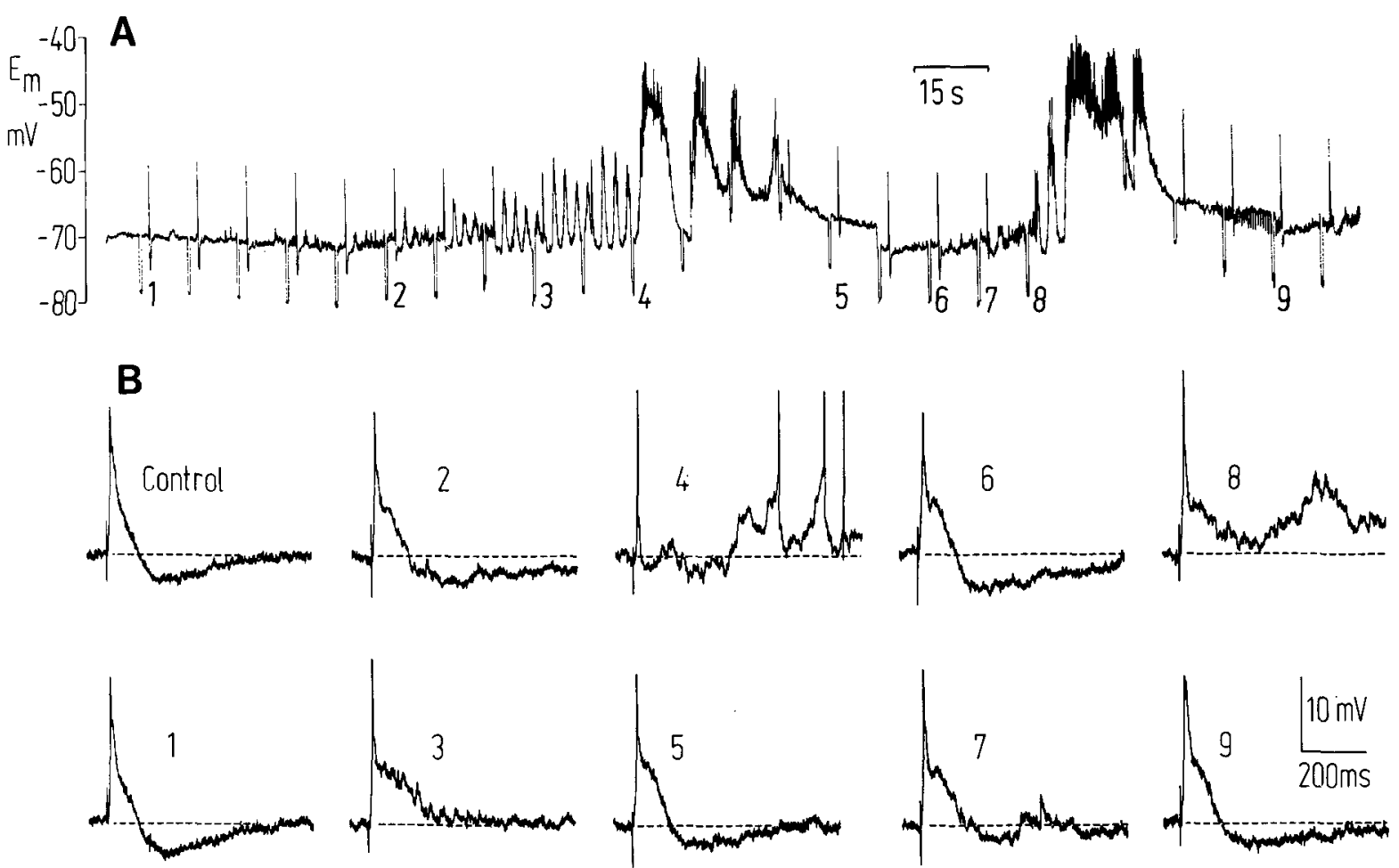

Fig. 7. Rhythmic loss of the late hyperpolarizing potential (LHP) associated with the onset and offset of seizure type neuronal discharges. A: a DC record of membrane potential with two major paroxysmal events. B: the membrane response (at high amplification) to a single LOT stimulus. The control was recorded before application of $10 \mu \mathrm{M} 4-\mathrm{AP}$ and the DC record starts 2 min after drug addition. The subsequent records were taken at the times indicated by the numbers in A. Note that just before onset of seizures ( 3 and 7) the LHP was reduced in amplitude. In the 'interictal' periods (6 and 9) it reappeared. Note also the very large spontaneous membrane potential oscillations evident before the first seizure discharge.

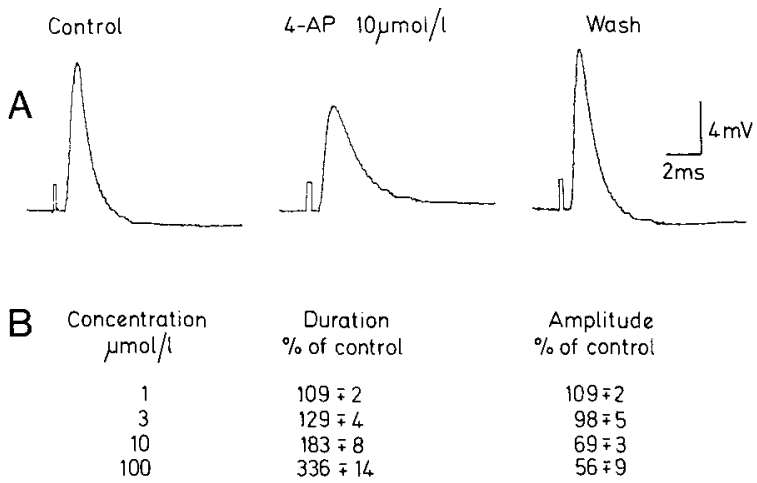

Fig. 8. A: averaged population potentials recorded from an isolated lateral olfactory tract. The traces are 10 sweeps at one per $5 \mathrm{~s}$; stimulus was $50 \mathrm{~V}, 0.1 \mathrm{~ms}$. The small square pulse is the stimulus artifact (retouched for clarity). Note how 4-AP caused a prolongation in the population spike and also reduced the amplitude. B: cumulative data obtained from 4 similar experiments. The values are means \pm S.E.M.; the duration was measured at $50 \%$ amplitude. 4-AP caused a dose-dependent increase in potential duration and above 3 $\mu \mathrm{M}$ some depression of amplitude. brane potential oscillations. How such a repetitive discharge could arise is not clear. It has been reported that 4-AP leads to slow oscillations and spike discharges in squid axons $\mathbf{1 4}^{\mathbf{1 4}, 32}$, however it is probable that this behaviour is not purely a consequence of delayed rectifier channel blockade ${ }^{14}$.

The fact that 4-AP prolonged the LOT fibre spike suggests that these fibres possess rectifying potassium channels sensitive to 4-AP. However the soma spike of paleocortical neurones was unchanged by the same concentrations (not illustrated). This is similar to our findings in rat ganglia ${ }^{11}$, where we observed that the soma spike was relatively unaffected by low concentrations of 4-AP (see also ref. 26) in contrast to vagus nerve $\mathrm{C}$-fibres which exhibited a marked prolongation of spike. It therefore appears as though there is 'site specificity' for delayed rectifier type channels; unmyelinated nerves containing many such channels and soma regions relatively few. 
In support of this is the finding that mammalian myelinated fibres possess few classical delayed rectifier channels ${ }^{3,20}$.

The convulsant discharges, which we recorded are different in character from any other seizure-type discharges recorded in olfactory cortex ${ }^{34}$ or hippocampa ${ }^{35,36}$ slice preparations. In both cases, convulsants such as bicuculline, penicillin and barium ions all lead to brief paroxysmal depolarizations but not to long duration depolarizations of 20-30 s. The large changes in extracellular ionic concentrations observed during 4-AP seizures are similar to those observed in vivo with other convulsants ${ }^{17}$. Indeed, superfusion of 4-AP over the anesthetized cat cortex produces similar ionic changes to those we have observed in the guinea-pig olfactory cortex slice (U. Heinemann, personal communication). This, at least, suggests that this in vitro model is similar to existing epileptic models.

Two major changes in neuronal function seemed to be contributing to the generation of convulsant activity in our preparation. Firstly, the increase in spontaneous transmitter release, which was evident in the minutes before and between seizure discharges. Secondly, the apparent loss of an IPSP shortly before paroxysmal depolarization. This latter effect has also been observed in the cat cortex during superfusion with 3 -aminopyridine ${ }^{1}$. The fact that the IPSP reappears in the 'interictal' period, despite the continuing presence of 4-AP, indicates that loss of
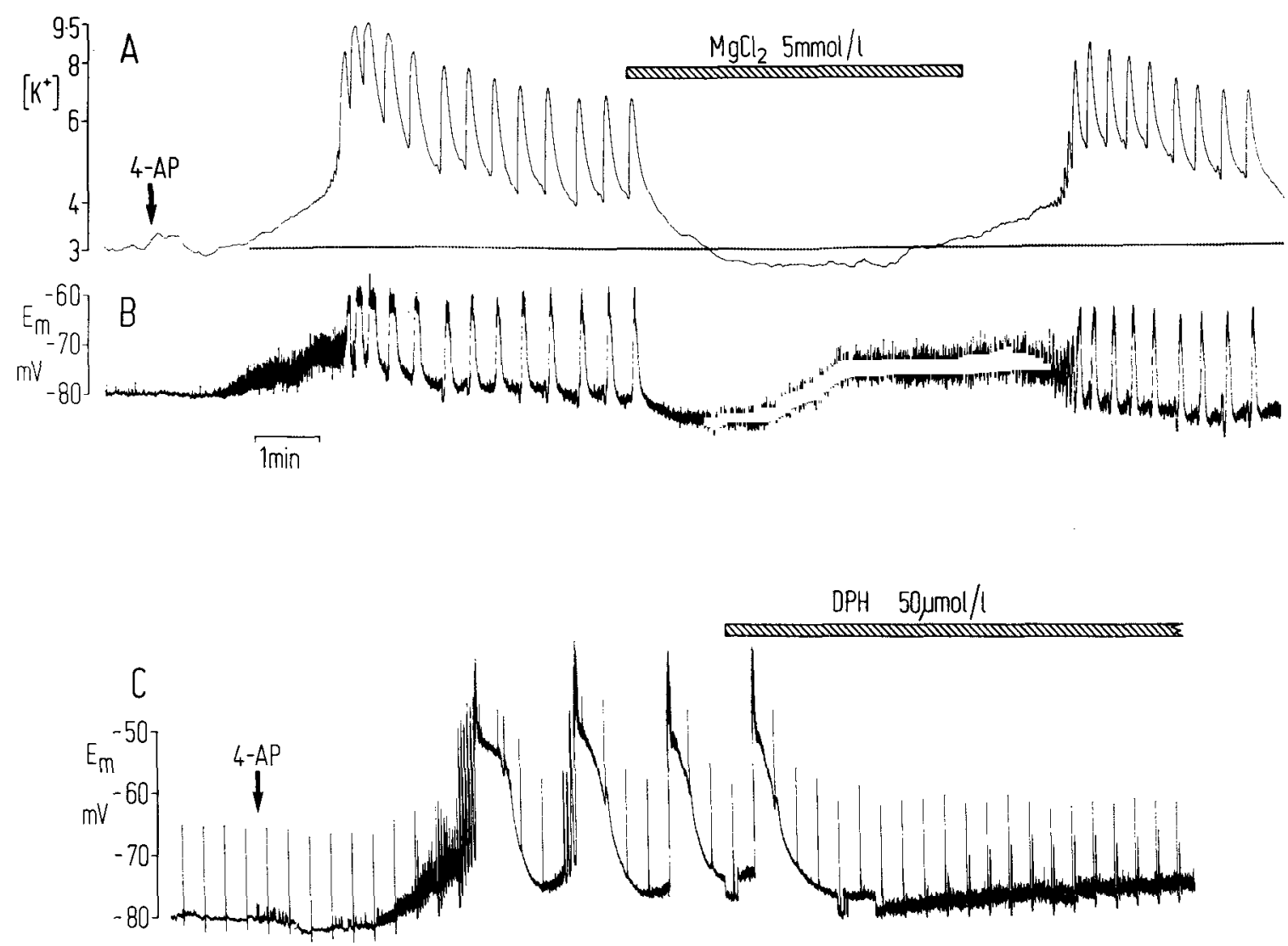

Fig. 9. Blockade of 4-AP-induced seizure discharges by magnesium and diphenylhydantoin. A and B: simultaneous recordings of membrane potential and extracellular potassium concentration. The arrow marks the start of superfusion with 10 $\mu \mathrm{M} 4$ 4-AP. After an initial rise in spontaneous potential frequency (accompanied by a rise in potassium) the cell and slice exhibited spontaneous rhythmic seizure discharges. These were quickly and reversibly abolished by raising the bath magnesium concentration by $5 \mathrm{mM}$ (hatched bar). C: recorded from another cell in another slice and shows how $50 \mu \mathrm{M}$ diphenylhydantoin could also arrest the rhythmic seizures elicited by $10 \mu \mathrm{M}$ 4-AP. The arrow marks the start of 4-AP application and the upward deflections were produced by intermittent stimulation of the LOT (not illustrated). Note how, in both examples, the spontaneous potentials continued even though the seizure discharges were abolished, 
inhibition does not simply result from a 4-AP antagonism of inhibitory transmitter receptors on the postsynaptic membrane. Our experiments in sympathetic ganglia ${ }^{11}$ and also in brain slices ${ }^{12}$ have quite clearly shown that 4-AP in concentrations up to 100 $\mu \mathrm{mol} / 1$ can only be, at best, a weak GABA antagonist. There is substantial evidence that GABA is one of the inhibitory transmitters operating in this cortical region ${ }^{4,6}$. However, the possibility exists that in the seconds before seizures commence, the cell sensitivity to inhibitory transmitter is reduced. Such a mechanism has been demonstrated during hippocampal seizures in vivo ${ }^{2}$. Furthermore, it is unlikely that the LHP disappears due to the 4-AP-induced rise in potassium, since this level was not more than 4-6 $\mathrm{mM}$ at the start of seizures. At these levels of extracellular potassium the LHP could still be recorded. The final possibility is that due to the increase in spontaneous activity, an inhibitory interneuronal pathway 'switches off' thus leading to instability in the circuit. Once the cell population has undergone paroxysmal depolarization, cell resistance falls and spontaneous potentials disappear (either due to a pre- or postsynaptic action) this then allows the interneurone to 'switch on' again.

Since $\mathrm{Mg}^{2+}$ could arrest seizure discharges, this implies that $\mathrm{Ca}^{2+}$ influx at either pre- or postsynap-

\section{REFERENCES}

1 Baranyi, A. and Fehér, O., Convulsive effects of 3-aminopyridine on cortical neurones, Electroenceph. clin. Neurophysiol., 47 (1979) 745-751.

2 Ben-Ari, Y., Krnjević, K. and Reinhart, W., Hippocampal seizures and failure of inhibition, Canad. J. Physiol. Pharmacol., 57 (1979) 1462-1466.

3 Brismar, T. and Frankenhaeuser, B., Potential clamp analysis of mammalian myelinated fibres, Trends Neurosci., 4 (1981) 68-70.

4 Brown, D. A. and Scholfield, C. N., Depolarization of neurones in the isolated olfactory cortex of the guinea-pig by $\gamma$-aminobutyric acid, Brit. J. Pharmacol., 65 (1979) 339-345.

5 Buckle, P. J. and Haas, H. L., Enhancement of synaptic transmission in rat hippocampal slices by 4-AP, Neurosci. Lett., Suppl. 7 (1981) S382.

6 Collins, G. G. S., Evidence of a neurotransmitter role for aspartate and $\gamma$-aminobutyric acid in the rat olfactory cortex, J. Physiol. (Lond.), 291 (1979) 51-60.

7 Constanti, A., Connor, J. D., Galvan, M. and Nistri, A., Intracellularly recorded effects of glutamate and aspartate on neurones in the guinea-pig olfactory cortex slice, Brain Research, 195 (1980) 403-420.

8 DiFrancesco, D., Hart, G., Noble, D. and Shimoni, Y., tic sites plays a role in the generation of paroxysmal depolarizations (see also ref. 35). The fact that spontaneous potentials were relatively unaffected, points to the latter site as the more likely possibility. Finally, the blockade of the 4-AP-induced seizure discharges by diphenylhydantoin (DPH) suggests that this model is suitable for testing the actions of anticonvulsants. In our preliminary communication $^{12}$, we showed how DPH could reversibly abolish all abnormal neuronal activity due to 4-AP. These experiments also showed that DPH had a very subtle effect on neuronal excitability, in that we detected no major change in membrane potential, input resistance, or IPSP duration. We therefore feel that, in this case, DPH may be acting at a presynaptic site. This could well be a consequence of its previously reported ability to slightly block sodium channels ${ }^{22,28}$.

\section{ACKNOWLEDGEMENTS}

We are extremely grateful to Peter Saggau, Florian Kolb and Karl-Heinz Zinnhobler for their assistance with programming and operation of the computer. This research was supported by a grant from the Deutsche Forschungsgemeinschaft $(\mathrm{Br}$ 242/16).

Voltage clamp currents at positive potentials in sheep Purkinje fibres: influence of $i_{f}$ and $\mathrm{K}$ accumulation, $J$. Physiol. (Lond.), 318 (1981) 29-30P.

9 Dingemanse, E. and Wibaut, J. P., Zur Pharmakologie von einigen Pyridylpyrrolen und einigen Abkömmlingen des $\alpha$-Aminopyridins, Arch, exp. Pathol. Pharmakol., 132 (1928) 365-381.

10 Galvan, M., Grafe, P. and ten Bruggencate, G., Facilitatory actions of guanidine on synaptic transmission in mammalian brain slices, Exp. Neurology, 67 (1980) 234-246.

11 Galvan, M., Grafe, P. and ten Bruggencate, G., Presynaptic actions of 4-aminopyridine and $\gamma$-aminobutyric acid on rat sympathetic ganglia in vitro, Naunyn-Schmiedeberg's Arch. Pharmacol., 314 (1980) 141-147.

12 Galvan, M., Grafe, P. and ten Bruggencate, G., Convulsive actions of 4-aminopyridine on neurones and extracellular $\mathrm{K}^{+}$and $\mathrm{Ca}^{++}$activities in guinea-pig olfactory cortex slices, In M. R. Klee, H.-D. Lux, and E.-J. Speckmann (Eds.), Physiology and Pharmacology of Epileptogenic Phenomena, Raven Press, New York, 1982, pp. 353-360.

13 Gilbey, M. P. and Wooster, M. J., Mono- and multisynaptic origin of the carly surface-negative wave recorded from the guinea-pig olfactory cortex in vitro, $J$. Physiol. (Lond.), 293 (1979) 153-172. 
14 Golenhofen, K. and Mandrek, K., Slow automatic activity in squid axons induced by 4 -aminopyridine, $J$. Physiol. (Lond.), 284 (1978) 69-70P.

15 von Haxthausen, E. F., Über Amino-Pyridin und seine Derivate, Arch. exp. Path. Pharmakol., 226 (1955) 163-171.

16 Halliwell, J. V., Synaptic interaction underlying piriform evoked responses studied in vitro, Exp. Brain Res., Suppl. 1 (1976) 223-228.

17 Heinemann, U., Lux, H. D. and Gutnick, M. J., Extracellular free calcium and potassium during paroxysmal activity in the cerebral cortex of the cat, Exp. Brain Res., 27 (1977) 237-243.

18 Jankowska, E., Lundberg, A., Rudomin, P. and Sykova, E., Effects of 4-aminopyridine on transmission in excitatory and inhibitory synapses in the spinal cord, Brain Research, 136 (1977) 387-392.

19 Jefferys, J. G. R., Aminopyridines modify granule cell response in guinea-pig hippocampal slices, J. Physiol. (Lond.), 312 (1981) 17P.

20 Kocsis, J. D. and Waxman, S. G., Absence of potassium conductance in central myelinated axons, Nature (Lond.), 287 (1980) 348-349.

21 Lemeignan, M., Analysis of the effects of 4-aminopyridine on the lumbar spinal cord of the cat. II - Modifications of certain spinal inhibitory phenomena, post-tetanic potentiation and dorsal root potentials, Neuropharmacology, 12 (1973) 641-651.

22 Lipicky, R. J., Gilbert, D. L. and Stillman, I. M., Diphenylhydantoin inhibition of sodium conductance in squid giant axon, Proc. nat. Acad. Sci. U.S.A., 69 (1972) 1758-1760.

23 Llinaś, R., Walton, K. and Bohr, V., Synaptic transmission in squid giant synapse after potassium conductance blockage with external 3- and 4-aminopyridine, Biophys. J., 16 (1976) 83-86.

24 Lundh, H. and Thesleff, S., The mode of action of 4aminopyridine and guanidine on transmitter release from motor nerve terminals, Europ. J. Pharmacol., 42 (1977) 411-412.

25 Matthews, G. and Wickelgren, W. O., Effects of guanidine on transmitter release and neuronal excitability, J. Physiol. (Lond.), 266 (1977) 69-89.

26 McAfee, D. A. and Yarowsky, P. J., Calcium-dependent potentials in the mammalian sympathetic neurone, $J$. Physiol. (Lond.), 290 (1979) 507-523.

27 Mori, K., Satau, M. and Takagi, S. F., Fast and slow inhibitory postsynaptic potentials in the piriform cortex neurones, Proc. Jap. Acad. Ser. B, 54 (1978) 484-489.

28 Neuman, R. S. and Frank, G. B., Effects of diphenylhydantoin and phenobarbital on voltage-clamped myelinated nerve, Canad., J. Physiol. Pharmacol., 55 (1977) 42-47.

29 Nicholson, C., ten Bruggencate, G., Stöckle, H. and Steinberg, R., Calcium and potassium changes in extracellular microenvironment of cat cerebellar cortex, J. Neurophysiol. 41 (1978) 1026-1039.

30 Nicoll, R. A. and Alger, B. E., Synaptic excitation may activate a calcium-dependent potassium conductance in hippocampal pyramidal cells, Science, 212 (1981) 957-959.

31 Pelhate, H. and Pichon, Y., Selective inhibition of potassium current in the giant axon of the cockroach, $J$. Physiol. (Lond.), 243 (1974) 90P.

32 Pichon, Y., Antagonistic effects of use dependent blockers of the potassium and sodium systems on repetitive activity in squid giant axons. In M. R. Klee, H.-D. Lux and E.-J. Speckman (Eds.), Physiology and Pharmacology of Epileptogenic Phenomena, Raven Press, New York, 1982, pp. 371-379.

33 Scholfield, C. N., A depolarizing inhibitory potential in neurones of the olfactory cortex in vitro, J. Physiol. (Lond.), 275 (1978) 547-558.

34 Scholfield, C. N., Convulsants antagonise inhibition in the olfactory cortex slice, Naunyn-Schmiedeberg's Arch. Pharmacol., 314 (1980) 29-36.

35 Schwartzkroin, P. A. and Prince, D. A., Cellular and field potential properties of epileptogenic hippocampal slices, Brain Research, 147 (1978) 117-130.

36 Schwartzkroin, P. A. and Prince, D. A., Changes in excitatory and inhibitory synaptic potentials leading to epileptogenic activity, Brain Research, 183 (1980) 61-76.

37 Sherratt, R. M., Bostock, H. and Sears, T. A., Effects of 4-aminopyridine on normal and demyelinated mammalian nerve fibres, Nature (Lond.), 283 (1980) 570-572.

38 Shimahara, T., Modulation of synaptic output by the transient outward potassium current in Aplysia, Neurosci. Lett., 24 (1981) 139-142.

39 Spyker, D. A., Lynch, C., Shabanowitz, J. and Sinn, J. A. Poisoning with 4-aminopyridine: report of three cases, Clin. Toxicol., 16 (1980) 487-497.

40 Szente, M. and Pongrácz, F., Aminopyridine-induced seizure activity, Electroenceph. clin. Neurophysiol., 46 (1979) 605-608.

41 Thesleff, S., Aminopyridines and synaptic transmission, Neuroscience, 5 (1980) 1413-1419.

42 Thompson, S. H., Three pharmacologically distinct potassium channels in molluscan neurones, $J$. Physiol. (Lond.)., 265 (1977) 465-488.

43 Ulbricht, W. and Wagner, H.-H., Block of potassium channels of the nodal membrane by 4-aminopyridine and its partial removal on depolarization, Pfiugers Arch., 367 (1976) 77-87.

44 Yanagisawa, T., Satoh, K. and Taira, N., Excitation of autonomic nerves by 4-aminopyridine in the isolated, blood-perfused sino-atrial node preparation of the dog, Europ. J. Pharmacol., 49 (1978) 189-192.

45 Yeh, J. Z., Oxford, G. S., Wu, C. H. and Narahashi, T., Interactions of aminopyridines with potassium channels of squid axon membranes, Biophys. J., 16 (1977) 77-81. 